\title{
Um patrimônio étnico: os prenomes de batismo
}

\author{
José Luiz da Veiga Mercer* \\ Sergio Odilon Nadalin**
}

Que há em um nome? ${ }^{1}$ Bem mais do que Romeu estaria disposto a ouvir, sobretudo quando se trata de prenomes, que podem revelar-se indicadores sociais preciosos. Enquanto os sobrenomes são cada vez mais impostos pelo sistema adotado pela sociedade, que não concede senão estreita margem de escolha, os prenomes são selecionados de um estoque usualmente grande, e podem até ser inventados. Onde há escolha, a própria escolha produz um significado. Afinal, por que este prenome e não aquele?

O significado produzido pela escolha se lê como uma preferência de época ou de grupo social, ou de ambos. A liberdade de escolha e seu efeito social abrem a porta para a moda, fenômeno ao qual os prenomes estão claramente submetidos. Este ou aquele prenome, antes raros, em determinado momento caem no gosto geral e se tornam muito frequentes. Ao contrário, há outros que nomeavam muitos homens e mulheres e, depois de certo tempo, começam a perder brilho, a escassear, a ponto de desaparecer. Pode acontecer, no entanto, que certos nomes sejam demandados não pelo conjunto da comunidade, mas apenas por certos grupos sociais, caracterizados por traços como renda, escolaridade, religião, origem étnica etc.

A escolha do prenome certamente não é um ato de absoluta liberdade: "está ligada ao sistema de parentesco, às regras de transmissão de bens reais e simbólicos, à ação do Estado e da Igreja, às normas do 'jogo social' próprias do grupo de pertencimento, enfim a um 'gosto' vivido como indivíduo mas socialmente determinado". ${ }^{2}$ A escolha se faz nos limites da tradição onomástica da comunidade, que se impõe aos pais porque o prenome é elemento da identidade social. ${ }^{3} \mathrm{O}$ prenome cumpre duas funções de identificação: por uma, de natureza primária, individualiza seu portador (este se chama Oscar, aquele se chama Arthur); ${ }^{4}$ por outra, secundária, revela o grupo social a que pertencem o portador e seus pais. A escolha de um prenome do estoque usual exprime a adesão ao grupo; é um ato de pertencimento. Já a escolha que ignorar o acervo tradicional poderá significar afastamento em relação à comunidade de origem e busca de uma nova identidade social. ${ }^{5}$

A ideia que anima o presente trabalho é a de que os prenomes podem sinalizar o processo de integração de um agrupamento étnico e religioso em Curitiba à sociedade receptora. Trata-se de imigrantes germânicos e seus descendentes, submetidos à tensão entre a lealdade a suas origens e a necessidade de adaptar-se ao novo mundo, procurando uns conservar as tradições tidas como dos antepassados, das quais outros vão se afastar. A utilização de pronomes em tal processo sociocultural pode ainda lançar luz sobre os aspectos linguísticos explorados nessa verdadeira "estilística dos prenomes", praticada coletivamente.

O trabalho consiste na análise da frequência dos prenomes dados a meninos e meninas dessa comunidade ao longo de cento e vinte anos. Os sujeitos da pesquisa são, pois, imigrantes oriundos da Europa germânica e seus descendentes que constituíram em Curitiba uma comunidade religiosa luterana e evangélica. Embora os primeiros imigrantes alemães tenham chegado ao Paraná em 1829, Curitiba só acolheria alemães em número relevante a partir de 1850, pela maioria remigrados de Joinville. Com o crescimento do grupo, em 1866 viabilizou-se a fundação formal da primeira Comunidade Evangélica de Curitiba, a "Deutsche Evangelische Gemeinde". Guardados na paróquia mais antiga (Cristo Redentor), os arquivos da Comunidade mantêm livros de registros de batismo (que constituíram a fonte da investigação), casamento e óbito.

Foram compiladas 19.291 ocorrências de prenomes de crianças nascidas em Curitiba - utilizados de forma isolada ou em combinação -, separadas em quatro períodos: 1866-1894, 1985-1919, 1920 1939 e 1940-1987. E, em classificação cruzada, foram divididas nos seguintes tipos de prenome:

\footnotetext{
* Professor aposentado do Departamento de Linguística, Letras Clássicas e Vernáculas da UFPR.

${ }^{* *}$ Professor do Departamento de História da UFPR, Pesquisador Bolsista do CNPq.
} 
- Prenomes "germânicos" do estoque imigrante (Karl, Gustav, Johann; Adelheid, Bertha, Marie).

- Prenomes flexíveis do estoque imigrante, etnicamente marcados (Arthur, Julius, Louis; Charlotte, Christine, Ellen).

- Prenomes flexíveis do estoque imigrante, etnicamente não-marcados (Daniel, David, Oscar; Alice, Anna, Maria).

- Prenomes fantasiosos, resultantes de má grafia ou de simples invenção, com base no estoque imigrante (Amand, Bentham, Kratt; Alberte, Erwine, Grunhild).

- Prenomes fantasiosos, resultantes de má grafia ou de simples invenção, com base no estoque teuto-brasileiro (Alarich, Karlos, Kratt; Edelsore, Guerrit, Rommy).

- Prenomes "germânicos" do estoque teuto-brasileiro (Ronald, Uwe, Walfried; Karin, Edda, Inge). ${ }^{6}$

- Prenomes portugueses correspondentes a prenomes germânicos (Carlos, Gustavo, João; Adelaide, Edithe, Luiza).

- Prenomes flexíveis do estoque teuto-brasileiro, etnicamente marcados (Boris, Harry, Marcus; Brigitte, Emily, Margot).

- Prenomes flexíveis do estoque teuto-brasileiro, etnicamente não-marcados (Felix, Levi, Nelson; Claudia, Carmem, Esther).

- Prenomes do estoque brasileiro (Cláudio, Mauro, Sílvio; Adelina, Cidália, Roseli).

- Prenomes fantasiosos, resultantes de simples invenção, com base no estoque brasileiro (Aldinar, Diloir, Glaucon; Aglásia, Eloylia, Sileze).

Esses tipos se justificam pela suposição de partida de que, num primeiro momento, os membros da comunidade utilizariam predominantemente nomes de um patrimônio germânico; na fase seguinte, ampliados os contatos, apareceriam prenomes de um estoque de transição, teuto-brasileiro; já na terceira e última etapa, que marcaria de maneira mais pronunciada a integração, haveria predominância de prenomes do estoque brasileiro. ${ }^{7}$

Qual era o estoque imigrante? De quais prenomes dispunham os imigrantes para nomear seus filhos? Impossível aceder a esses dados, que existiram como mera virtualidade. Para superar esse entrave metodológico, optou-se por considerar que faziam parte desse estoque original os prenomes trazidos pelos imigrantes e utilizados no batismo das crianças nascidas de 1866 a 1919 . Esse repertório não se compunha apenas de nomes de origem germânica, já que a onomástica alemã moderna se caracteriza não só por uma tradicional influência bíblica, ${ }^{8}$ mas também por grande abertura para nomes de estrangeira - grega, latina, francesa, italiana, espanhola, inglesa e outras -, tais como: Louis, Caesar, Guido, Henry, Nelson, Alice, Dorothea, Cecilia, Charlotte, Dolores, Mercedes. Disso resultou que o estoque imigrante mantivesse certa margem de coincidência com o estoque utilizado pelos brasileiros, o que poderia ser utilizado, consciente ou inconscientemente, como solução de compromisso entre a lealdade devida à cultura germânica e a necessidade de aproximação da cultura brasileira. Os prenomes coincidentes foram destacados como "prenomes flexíveis", tal como o fez João Udo Siemens."

A experiência de trabalho com os dados mostrou a necessidade de separar os prenomes flexíveis em dois grupos: etnicamente marcados, aqueles que, por sua grafia ${ }^{10}$ ou sua frequência entre os imigrantes, ficavam assim marcados, e etnicamente não-marcados, os demais, que não tinham efeito distintivo.

Prenomes da onomástica germânica utilizados primordialmente depois de 1919 foram agrupados, conforme o caso, como prenomes "germânicos" do estoque teuto-brasileiro; prenomes flexiveis do estoque teutobrasileiro, etnicamente marcados; e prenomes flexiveis do estoque teuto-brasileiro, etnicamente não-marcados. Por motivo análogo ao dos prenomes flexíveis, foram isolados os prenomes portugueses correspondentes aos germânicos (Carlos - Karl; Frederico - Friedrich; João -Johann). Utilizados até pelos pioneiros, também representaram uma negociação entre as duas faces culturais da comunidade, a alemã e a brasileira.

Os prenomes fantasiosos são entendidos como forma de afastamento em relação a um cânone e por esse motivo constituíram novos tipos de prenomes. Quanto ao estoque brasileiro, cabe observar que nele não se computaram os itens registrados como prenomes flexíveis.

Os prenomes arrolados foram computados e organizados na forma da Tabela 1, a seguir. 


\begin{tabular}{|c|c|c|c|c|c|c|c|c|c|c|c|c|c|c|c|}
\hline & & ثே & 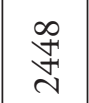 & $\begin{array}{l}\vec{\sim} \\
\widetilde{\sim}\end{array}$ & 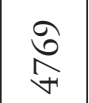 & 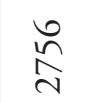 & స్ర్ర & $\underset{\sim}{\stackrel{\infty}{\sharp}}$ & $\stackrel{m}{\stackrel{n}{N}}$ & $\begin{array}{l}\infty \\
\substack{\infty \\
\infty}\end{array}$ & $\underset{\substack{+\infty}}{\infty}$ & 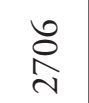 & $\underset{\stackrel{+}{\sim}}{\stackrel{\sim}{\sim}}$ & $\hat{n}$ & নે \\
\hline \multirow{11}{*}{ 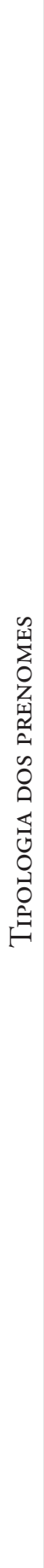 } & \multirow{2}{*}{ 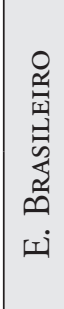 } & $\begin{array}{l}\text { 11. Fantasiosos } \\
\text { do e. bras. }\end{array}$ & 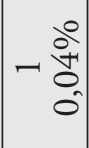 & n & $6 \frac{0}{0}$ & ヘ ัे & तิ & min & nn & $\infty \stackrel{\circ}{\stackrel{9}{\sim}}$ & ma & $\stackrel{\infty}{=} \underset{\sim}{\stackrel{2}{+}}$ & 잉 & 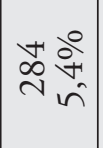 & 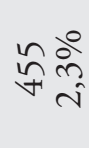 \\
\hline & & 10. Brasileiros & $=\stackrel{\substack{0 \\
0 \\
0}}{0}$ & ते & mî & $\stackrel{2}{=}$ & 文 & $\underset{\sim}{\stackrel{2}{*}} \stackrel{\circ}{\forall}$ & $\begin{array}{ll}0 & 0 \\
m & m \\
m & 0\end{array}$ & 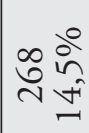 & 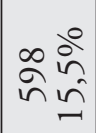 & $\begin{array}{ll}n & 0 \\
0 & 0 \\
- & 0 \\
0\end{array}$ & $\begin{array}{l}m a \\
\stackrel{2}{\sigma} \sigma \\
\end{array}$ & 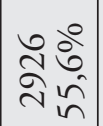 & $\begin{array}{l}m \delta^{\circ} \\
\infty \\
m \\
m\end{array}$ \\
\hline & \multirow{6}{*}{ 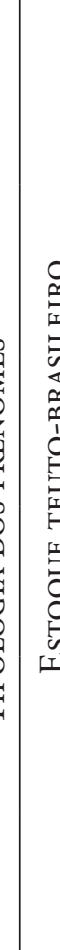 } & $\begin{array}{l}\text { 9. Flexíveis não- } \\
\text { marcados do e. } \\
\text { t-b }\end{array}$ & ' & 1 & ' & $\ln \frac{0}{0}$ & ' & n $\frac{0}{0}$ & i $\stackrel{\substack{+=}}{=}$ & $\begin{array}{l}n \\
n \\
\sim \\
0 \\
0 \\
0\end{array}$ & $\stackrel{2}{2}=$ & « & $\operatorname{nin} \frac{0}{i}$ & $\left|\begin{array}{ll}\infty & 0 \\
0 & 0 \\
- & 0 \\
i\end{array}\right|$ & 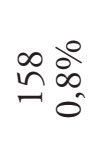 \\
\hline & & $\begin{array}{l}\text { 8. Flexíveis mar- } \\
\text { cados do e. } \mathrm{t}-\mathrm{b}\end{array}$ & & & 1 & $-\stackrel{\substack{0 \\
0 \\
0}}{0}$ & 1 & $-\frac{0}{0}$ & ○ & $=\begin{array}{l}0 \\
0 \\
0\end{array}$ & $=\stackrel{0}{\stackrel{0}{+}}$ & $-\begin{array}{c}0 \\
0 \\
0 \\
0\end{array}$ & & $\begin{array}{r}- \\
0 \\
0 \\
0\end{array} \mid$ & $\approx 8^{\circ}$ \\
\hline & & $\begin{array}{l}\text { 7. Portugueses } \\
\text { correspondentes }\end{array}$ & Gr & $\begin{array}{ll}\circ & \stackrel{0}{\sim} \\
\end{array}$ & $\begin{array}{ll}1 & 0 \\
m & 0 \\
- & 0\end{array} \mid$ & $\hat{n}$ & ํํำ & 官余 & 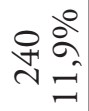 & 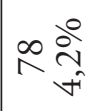 & 交 & $\stackrel{2}{2} \stackrel{0}{=}$ & 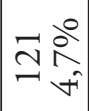 & $\begin{array}{ll}n & \stackrel{0}{a} \\
m & n^{2}\end{array}$ & $\begin{array}{l}\text { Tิ } \\
\text { O } \\
\text { in }\end{array}$ \\
\hline & & $\begin{array}{l}\text { 6. Germmânicos } \\
\text { do e t-b }\end{array}$ & 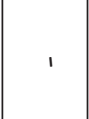 & & 1 & $=$ aे & 1 & $=\stackrel{0}{\text { ஸे }}$ & 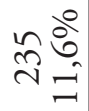 & $=$ बे & 党 & ก̊ & $\begin{array}{l}\infty \\
\infty \\
\infty \\
\infty\end{array}=$ & $\mid \begin{array}{l}0 \\
0 \\
i n \\
n \\
0 \\
0\end{array}$ & $\begin{array}{l}m \stackrel{0}{\circ} \\
=i n\end{array}$ \\
\hline & & $\begin{array}{l}\text { 5. Fantasiosos } \\
\text { do e. } \mathrm{t}-\mathrm{b}\end{array}$ & $+\frac{a}{0}$ & m & 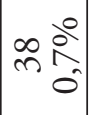 & $\overrightarrow{2} \stackrel{\stackrel{0}{0}^{\circ}}{0}$ & ํํㅇ & $\stackrel{2}{n}$ & 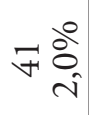 & $\hat{\sigma} \dot{m}^{\circ}$ & $\begin{array}{ll}\infty & 0 \\
0 & 0 \\
0 & \infty \\
-1\end{array}$ & $\underset{\forall}{*}$ & n̊ & $\bar{\infty} \stackrel{\stackrel{0}{2}}{\stackrel{2}{n}}$ & 8요 \\
\hline & & $\begin{array}{l}\text { 4. Fantasiosos } \\
\text { do e. o. }\end{array}$ & $\backsim \begin{array}{l}n \\
0 \\
0 \\
0\end{array}$ & 욕 & 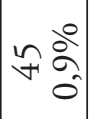 & $\begin{array}{l}\infty \\
- \\
0 \\
0\end{array}$ & 芕迅 & 징 & $=\begin{array}{l}0 \\
i n \\
0\end{array}$ & ๙ & ले & $-\begin{array}{r}0^{0} \\
\hat{0} \\
0\end{array}$ & N $\begin{array}{l}\hat{O}_{0}^{0} \\
0\end{array}$ & 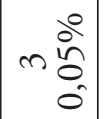 & $\stackrel{a}{\stackrel{+}{0}}$ \\
\hline & \multirow{3}{*}{ 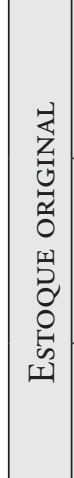 } & $\begin{array}{l}\text { 3. Flexíveis não- } \\
\text { marcados do } \\
\text { e. o. }\end{array}$ & \# & $\stackrel{20}{*}$ & 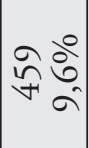 & m $\stackrel{\substack{+0}}{0}$ & m & 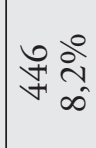 & in & त & 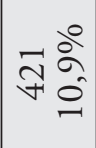 & ㅎํㄹㅇㅛ & 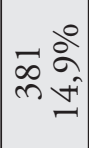 & $\left|\begin{array}{ll}\infty & 0 \\
\multirow{+}{*}{} & \frac{0}{\infty}\end{array}\right|$ & 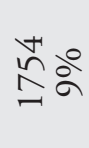 \\
\hline & & $\begin{array}{l}\text { 2. Flexíveis mar- } \\
\text { cados do } \\
\text { e. } 0 .\end{array}$ & $\begin{array}{ll}0 & 0 \\
= & \stackrel{8}{\forall}\end{array}$ & \begin{tabular}{ll}
$\infty$ & 0 \\
\multirow{1}{*}{} & 0 \\
& 0 \\
0 & 0
\end{tabular} & 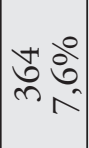 & $\begin{array}{ll}0 & 0 \\
0 & \infty \\
-1 & \infty\end{array}$ & 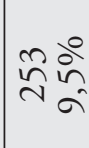 & $\frac{m}{F} b^{\circ}$ & ㅇํํ & $\mid \begin{array}{ll}\infty & 0 \\
0 & 0 \\
0 & \infty \\
-1 & 1\end{array}$ & 花 & m & m & 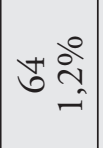 & 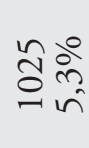 \\
\hline & & 1. Germânicos & 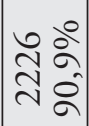 & \begin{tabular}{ll}
$\infty$ & 0 \\
1 & 0 \\
\multirow{1}{*}{} & 0 \\
$\sigma$ & 0
\end{tabular} & 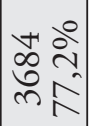 & 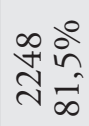 & 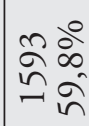 & 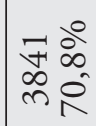 & 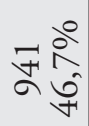 & ㅎํㅅำ & 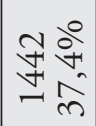 & $\begin{array}{ll}\infty & 0 \\
\infty & 0 \\
\sim & 0 \\
& 0\end{array}$ & $\vec{\sim}$ & 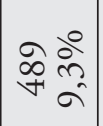 & 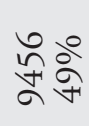 \\
\hline & \multirow{2}{*}{\multicolumn{2}{|c|}{ 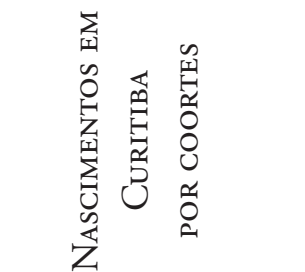 }} & ro & O+ & 퓽 & ro & O+ & 퓸 & ro & O+ & تేّ & ro & $\mathrm{O}+$ & تేّ & \multirow{2}{*}{ 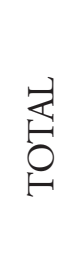 } \\
\hline & & & \multicolumn{3}{|c|}{ 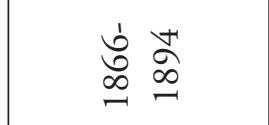 } & \multicolumn{2}{|c|}{$\stackrel{\dot{\alpha}}{\infty} \underset{\approx}{\sigma}$} & & \multicolumn{3}{|c|}{ ڤે } & \multicolumn{3}{|c|}{$\begin{array}{l}\dot{1} \\
\stackrel{2}{2} \\
2\end{array}$} & \\
\hline
\end{tabular}


Os números totais têm, antes do mais, um interesse metodológico, pois mostram que produziram quantitativos apreciáveis os tipos de prenomes que permitem alguma forma de negociação cultural por via da ambivalência. Aí se computam os prenomes ambíguos - os prenomes flexíveis e os prenomes portugueses correspondentes a germânicos -, os quais perfazem 4.035 ocorrências, ou seja, praticamente $21 \%$ do total. ${ }^{11}$

Ainda considerando uma visão mais ampla da tabela, chama a atenção o expressivo total de nomes germânicos no período - 9.456 - que ultrapassa a soma de todos os prenomes que, ambíguos ou não, possam ser interpretados como brasileiros (8.273). No mais, o conjunto dos números aponta para um fenômeno interessante: os prenomes masculinos e femininos seguem caminhos paralelos, separados por intervalos percentuais nítidos. Finalmente, conforme era esperado, as ocorrências de prenomes germânicos decrescem regularmente ao longo do período, enquanto cresce a frequência dos brasileiros, balizando o processo de contatos culturais.

Essa evolução, como já assinalado, se dá no quadro da contraposição de dois movimentos: a lealdade para com a cultura germânica e a pressão no sentido da cultura brasileira. Nessa antítese, atuam como elementos contraditórios os prenomes ambíguos há pouco mencionados. Assim, os números contidos nessa tabela podem ser lidos segundo duas orientações: a paulatina perda da lealdade e a crescente integração. Na primeira leitura, os prenomes ambíguos contam como marcadores de germanidade, somando-se aos demais prenomes de cunho germânico, em oposição ao estoque brasileiro (Tabela 2); na segunda, como marcadores de brasilidade, somando-se ao estoque brasileiro, em oposição aos prenomes de cunho germânico (Tabela 3).

Tabela 2: Evolução da lealdade onomástica

\begin{tabular}{|c|c|c|c|c|c|c|c|c|}
\hline \multirow{3}{*}{ SEXo } & \multicolumn{7}{|c|}{ PERÍODO } \\
\cline { 2 - 9 } & \multicolumn{2}{|c|}{$1866-1894$} & \multicolumn{2}{|c|}{$1895-1919$} & \multicolumn{2}{c|}{$1920-1939$} & \multicolumn{2}{c|}{$1940-1987$} \\
\cline { 2 - 9 } & GERM + & BRAS - & GERM + & BRAS - & GERM + & BRAS - & GERM + & BRAS - \\
\hline \multirow{3}{*}{$\lesssim$} & 2436 & 12 & 2634 & 122 & 1630 & 383 & 935 & 1771 \\
& $99,5 \%$ & $0,4 \%$ & $95,5 \%$ & $4,4 \%$ & $80,9 \%$ & $19 \%$ & $34,5 \%$ & $65,4 \%$ \\
\hline \multirow{2}{*}{+} & 2291 & 30 & 2527 & 135 & 1490 & 346 & 1110 & 1439 \\
& $98,7 \%$ & $1,2 \%$ & $94,9 \%$ & $5 \%$ & $81,1 \%$ & $18,8 \%$ & $43,1 \%$ & $56,8 \%$ \\
\hline \multirow{2}{*}{ TotAL } & 4729 & 42 & 5161 & 257 & 3120 & 729 & 2045 & 3210 \\
& $99,1 \%$ & $0,8 \%$ & $98,2 \%$ & $1,7 \%$ & $81 \%$ & $18,9 \%$ & $38,9 \%$ & $61 \%$ \\
\hline
\end{tabular}

Fonte: Comunidade Evangélica Luterana de Curitiba - Registros de Batismos. GERM +: prenomes germânicos mais prenomes ambiguos (col. 1 a 9 da Tab. 1). BRAS -: prenomes luso-brasileiros menos pronomes ambíguos (col. 10 e 11 da Tab. 1).

Os prenomes ambíguos têm os seguintes totais: 1866-1894, 20,2\%; 1895-1919, 24,7\%; 19201939, 25,5\%; 1940-1987, 17,5\%. São esses percentuais que, de uma tabela para outra, serão deslocados da germanidade para a brasilidade. Observe-se que são valores altos, podendo chegar a um quarto dos prenomes do período.

A comunidade se mostrou fortemente leal ao patrimônio germânico até o período 1920-1939, quando a frequência de prenomes germânicos ainda atingia $81 \%$. Já no período seguinte, que se encerra em 1987, o percentual cai para praticamente 39\%. Durou, portanto, bem mais de meio século o intenso apego a esses símbolos étnicos, que permaneceu expressivo mesmo no último período pesquisado, registrando-se algo como dois quintos de prenomes ligados à onomástica de origem.

Quanto à lealdade, não há diferenças significativas entre homens e mulheres. Por comparação com os meninos, observa-se ligeiro desprendimento na escolha do prenome para as meninas até 1919, o que se inverte daí por diante, quando os prenomes masculinos estarão menos presos à onomástica de origem que os prenomes femininos. 
Tabela 3: Evolução da integração onomástica

\begin{tabular}{|c|c|c|c|c|c|c|c|c|}
\hline \multirow{3}{*}{ Sexo } & \multicolumn{8}{|c|}{ Período } \\
\hline & \multicolumn{2}{|c|}{ 1866-1894 } & \multicolumn{2}{|c|}{$1895-1919$} & \multicolumn{2}{|c|}{ 1920-1939 } & \multicolumn{2}{|c|}{ 1940-1987 } \\
\hline & GERM - & BRAS + & GERM - & BRAS + & GERM - & BRAS + & GERM - & BRAS + \\
\hline $0^{\lambda}$ & $\begin{array}{c}2245 \\
91,7 \%\end{array}$ & $\begin{array}{c}203 \\
8,2 \%\end{array}$ & $\begin{array}{c}2298 \\
83,3 \%\end{array}$ & $\begin{array}{c}458 \\
16,6 \%\end{array}$ & $\begin{array}{l}1228 \\
61 \%\end{array}$ & $\begin{array}{c}785 \\
38,9 \%\end{array}$ & $\begin{array}{c}606 \\
22,3 \%\end{array}$ & $\begin{array}{c}2100 \\
77,6 \%\end{array}$ \\
\hline q & $\begin{array}{c}1522 \\
65,5 \%\end{array}$ & $\begin{array}{c}799 \\
34,4 \%\end{array}$ & $\begin{array}{c}1689 \\
63,4 \%\end{array}$ & $\begin{array}{c}973 \\
36,5 \%\end{array}$ & $\begin{array}{c}907 \\
49,4 \%\end{array}$ & $\begin{array}{c}929 \\
50,5 \%\end{array}$ & $\begin{array}{c}523 \\
20,5 \%\end{array}$ & $\begin{array}{c}2026 \\
79,4 \%\end{array}$ \\
\hline TотAL & $\begin{array}{c}3767 \\
78,9 \%\end{array}$ & $\begin{array}{l}1002 \\
21 \%\end{array}$ & $\begin{array}{l}3987 \\
73,5\end{array}$ & $\begin{array}{c}1431 \\
26,4 \%\end{array}$ & $\begin{array}{c}2135 \\
55,4 \%\end{array}$ & $\begin{array}{c}1714 \\
44,5 \%\end{array}$ & $\begin{array}{c}1129 \\
21,4 \%\end{array}$ & $\begin{array}{c}4126 \\
78,5 \%\end{array}$ \\
\hline
\end{tabular}

Fonte: Comunidade Evangélica Luterana de Curitiba - Registros de Batismos. GERM -: prenomes germânicos menos prenomes ambíguos (col. 1, 4, 5 e 6 da Tab. 1). BRAS +: prenomes luso-brasileiros mais pronomes ambiguos (col. 2, 3, 7, 8, 9, 10 e 11 da Tab. 1).

A Tabela 3 mostra que, graças sobretudo aos prenomes ambíguos, já no primeiro período se registra um quinto de prenomes ligados à onomástica brasileira. Essa parcela crescerá timidamente até 1919, mas fará um salto no período que precede a Segunda Guerra, ampliando-se fortemente no último período estudado. Quanto aos prenomes femininos "brasileiros", estes partem com boa dianteira em relação aos masculinos e manterão posição até o final, embora a diferença percentual vá diminuindo até reduzir-se a menos de $2 \%$.

O efeito da ambiguidade dos prenomes flexíveis é marcante no período de 1920 a 1939, em que representam um quarto dos prenomes. Do ponto de vista da lealdade, o período ostenta um percentual de $81 \%$ (Tabela 2) de prenomes ligados à onomástica germânica; já do ponto de vista da integração, esse índice de etnicidade cai para 55,4\% (Tabela 3), de sorte que as onomásticas germânica e brasileira quase entram em equilíbrio nessa etapa. A ambiguidade dos prenomes produz uma imagem que pode ser traduzida assim: a comunidade segue intensamente apegada a um patrimônio de prenomes de origem "alemã”, mas já se encontra a meio caminho de sua integração às tradições da sociedade receptora. Embora estranha, a formulação possibilita captar a duplicidade de leitura que permite esse arranjo onomástico.

A aferição da lealdade aos nomes de origem germânica poderia ser complementada pelo exame da coincidência de prenomes favoritos, em cada época, na Alemanha e na comunidade evangélica dos luteranos em Curitiba. A fonte alemã mais acessível é o sítio <www.beliebte-vornamen.de>, que, no entanto, apresenta algumas limitaçôes para o cotejo: seus levantamentos se iniciam em 1890 e se circunscrevem à Alemanha setentrional. Além disso, a preferência por um prenome é indicada por sua presença em listas anuais, sem que se possa fazer um cálculo cumulativo de ocorrências. Com o intuito de ao menos se fazer uma ideia sobre o grau de coincidência, foram cotejadas as listas de frequência de prenomes em Curitiba com as listas anuais em igual período na Alemanha. ${ }^{12} \mathrm{~A}$ Tabela 4, a seguir, indica o percentual de prenomes curitibanos que figuram nas listas alemãs entre 1866 e1939, período no qual se mostrou mais evidente a construção de uma identidade étnica na comunidade:

Tabela 4: Prenomes curitibanos presentes nas listas de preferência alemãs

\begin{tabular}{|c|c|c|c|}
\hline \multirow{2}{*}{ SEXO } & \multicolumn{3}{|c|}{ PERÍODO } \\
\cline { 2 - 4 } & $1866-1894$ & $1895-1919$ & $1920-1939$ \\
\hline \multirow{0}{*}{} & $72,7 \%(24 / 33)$ & $58,3 \%(28 / 48)$ & $49,1 \%(29 / 59)$ \\
\hline 0 & $50,0 \%(19 / 38)$ & $51,7 \%(29 / 56)$ & $41,1 \%(28 / 68)$ \\
\hline
\end{tabular}

Fontes: www.beliebte-vornamen.de; Comunidade Evangélica Luterana de Curitiba - Registros de Batismos. 
Os percentuais se distribuem de forma semelhante à que se viu na tabela anterior: a forte adesão inicial vai se enfraquecendo com o passar dos anos, numa curva que é mais marcada entre os prenomes masculinos que nos prenomes femininos. Os nomes dos meninos começam por um alto percentual de coincidência e caem mais de 23 pontos percentuais até 1939, enquanto os prenomes femininos têm por ponto de partida o que os masculinos levarão 45 anos para alcançar, mas, em compensação, declinam apenas 9 pontos até 1939 .

Os dados até aqui examinados mostram que os pais não se conduziram da mesma forma com relação aos prenomes dos filhos segundo fossem meninas ou meninos. Isso permite imaginar um cenário em que as famílias estariam mais sujeitas a pressóes sociais na escolha de nomes para os meninos do que na escolha para as meninas. Alguns aspectos dessa diferença de tratamento devem remontar à matriz europeia, como a composição dos estoques de prenomes. Como já mencionado, a onomástica alemã moderna se caracteriza por notável abertura para os nomes estrangeiros, maior no caso de prenomes femininos que entre os masculinos, como se comprova pelas listas anuais de nomes preferidos. ${ }^{13}$ Esses traços se transmitiram aos luteranos de Curitiba, que dão igualmente amplo lugar aos prenomes estrangeiros, e mais generosamente com o estoque feminino do que com o masculino. Assim é que, no período de 1866-1894, por exemplo, o estoque de prenomes estava composto como indicado na Tabela 5:

Tabela 5: Origem dos prenomes no período 1866-1894

\begin{tabular}{|c|c|c|c|}
\hline SEXo & FORMAS ENDÓGENAS & Formas ALÓGENAS & TOTAIS \\
\hline$\delta$ & $67(37,4 \%)$ & $112(62,5 \%)$ & 179 \\
\hline$q$ & $30(13,5 \%)$ & $191(86,4 \%)$ & 221 \\
\hline Total & $97(24,2 \%)$ & $303(75,7 \%)$ & 400 \\
\hline
\end{tabular}

Fonte: Comunidade Evangélica Luterana de Curitiba - Registros de Batismos.

Arredondados os números, pode-se dizer que apenas um em quatro prenomes era de formação germânica; os demais eram resultantes de empréstimo cultural. E como se antecipou, esses empréstimos foram mais frequentes junto aos nomes de meninas, com quase 24 pontos percentuais à frente dos empréstimos masculinos.

No contexto europeu, a abertura para os empréstimos tem sido um desdobramento de fenômeno mais geral, que é o da ampliação do estoque de prenomes, sobretudo a partir do séc. XVIII. ${ }^{14} \mathrm{~A}$ inflação de tipos antroponímicos tem se dado às expensas dos mecanismos tradicionais de nominação, que privilegiavam a repetição de nomes, particularmente de parentes, de padrinhos e dos santos do dia do nascimento. E são os prenomes femininos que lideram o processo de alargamento do estoque, ${ }^{15}$ o que se pode explicar pela condição feminina de minus habens, pelo qual seu papel social e econômico era restrito e depreciado por comparação àqueles reservados aos homens. Com pouco peso econômico e ainda menos responsabilidade social, a mulher se aprestava a inovaçóes onomásticas, de que os rapazes, por prudência, deviam ficar mais resguardados. ${ }^{16}$

No interior da comunidade luterana de Curitiba, deve-se atribuir à diferença nos papéis reservados a homens e mulheres o comportamento dos prenomes masculinos quanto à lealdade onomástica, como visto na Tabela 1. Os pais, que inicialmente se mostravam seguidores dos padrões alemães antes com os nomes dos meninos do que com os das meninas, a partir de 1920 invertem a relação, ficando os prenomes femininos mais próximos das tradições alemãs. Deve ter sido esse o momento em que se resolveu uma situação conflituosa: de um lado, a obrigação de lealdade à sociedade emissora impunha a onomástica alemã; de outro, a necessidade de inserção dos rapazes no mercado de trabalho e na rede de relaçôes com a sociedade receptora pedia nomes brasileiros.

Que havia um impasse cultural a ser resolvido fica bem claro também quando se cotejam os nomes dados ao primeiro e ao último filho, como se pode ver na Tabela 6 . Esse quadro agrupa resultados de um 
estudo longitudinal que acompanhou dois grupos de famílias. Como não se está trabalhando com todas as famílias, o número total de prenomes baixa de 19.291 para 3.530 itens, o que, no entanto, é suficiente para comprovar que os casais - pressionados pelos valores étnicos que, mais ou menos conscientemente, moldavam as atitudes do grupo - tenderiam a privilegiar os primeiros filhos com prenomes mais conservadores. Dada uma satisfação à comunidade, a pressão da etnicidade interferiria cada vez menos à medida que evoluía o ciclo matrimonial, e a observação do último filho poderia esclarecer a questão.

Tabela 6: Escolha do primeiro nome em função da categoria de prenome e da ordem de nascimento (primogênito e ultimogênito)

\begin{tabular}{|c|c|c|c|c|c|}
\hline \multirow{3}{*}{\multicolumn{2}{|c|}{$\begin{array}{l}\text { NASCIMENTOS } \\
\text { EM CURITIBA } \\
\text { POR COORTES }\end{array}$}} & \multicolumn{4}{|c|}{ ProcedÊNCIA DO PRENOME } \\
\hline & & \multicolumn{2}{|c|}{ Estoque de Origem } & \multicolumn{2}{|c|}{ Outro Estoque } \\
\hline & & MASC & FEMIN & MASC & FEMIN \\
\hline \multirow{4}{*}{$\begin{array}{l}1866 \\
1894\end{array}$} & \multirow{2}{*}{$1^{\circ}$} & 182 & 121 & - & 009 \\
\hline & & $100 \%$ & $93 \%$ & - & $6,9 \%$ \\
\hline & \multirow{2}{*}{ último } & 160 & 127 & 008 & 017 \\
\hline & & $95,2 \%$ & $88,1 \%$ & $4,7 \%$ & $11,8 \%$ \\
\hline \multirow{4}{*}{$\begin{array}{l}1895 \\
1919\end{array}$} & \multirow{2}{*}{$1^{\circ}$} & 197 & 172 & 036 & 030 \\
\hline & & $84,5 \%$ & $85,1 \%$ & $15,4 \%$ & $14,8 \%$ \\
\hline & \multirow{2}{*}{ último } & 160 & 134 & 059 & 082 \\
\hline & & $73 \%$ & $62 \%$ & $26,9 \%$ & $37,9 \%$ \\
\hline \multirow{4}{*}{$\begin{array}{l}1920 \\
1939\end{array}$} & \multirow{2}{*}{$1^{\circ}$} & 105 & 073 & 137 & 140 \\
\hline & & $43,3 \%$ & $34,2 \%$ & $56,6 \%$ & $65,7 \%$ \\
\hline & \multirow{2}{*}{ último } & 074 & 061 & 148 & 172 \\
\hline & & $33,3 \%$ & $26,1 \%$ & $66,6 \%$ & $73,8 \%$ \\
\hline \multirow{4}{*}{$\begin{array}{l}1940 \\
1987\end{array}$} & \multirow{2}{*}{$1^{\circ}$} & 040 & 022 & 240 & 261 \\
\hline & & $14,2 \%$ & $7,7 \%$ & $85,7 \%$ & $92,2 \%$ \\
\hline & \multirow{2}{*}{ último } & 025 & 016 & 265 & 257 \\
\hline & & $8,6 \%$ & $5,8 \%$ & $91,3 \%$ & $94,1 \%$ \\
\hline
\end{tabular}

Fonte: Comunidade Evangélica Luterana de Curitiba - Registros de Batismos.

Ainda aqui se observa que a cautela dos pais se exprime na preferência por nomes de características identitárias bem marcadas no caso de filhos do sexo masculino, em praticamente todas as coortes. A ênfase na identificação dos meninos revela o caráter conservador do grupo, com as poucas exceções indicadas pelos números.

É de se supor que a dinâmica do processo de afastamento em relação ao patrimônio original tenha sido influenciada pelo próprio efeito inercial das escolhas de prenomes feitas em momentos anteriores, na forma de uma reinterpretação da tradição onomástica, cada vez mais tolerante. A percepção dos limites entre a onomástica germânica e a brasileira vai se enfraquecendo à medida que as geraçóes se sucedem e se incorporam um número cada vez maior de prenomes "novos". Do ponto de vista dos membros da comunidade, que não têm consciência documental do conjunto de prenomes legados pelos pioneiros, senão uma percepção do uso contemporâneo, o alargamento do estoque pode ser interpretado como uma ampliação de seu mundo étnico.

É que essa percepção, aguda para certo número de prenomes, certamente comporta áreas de vagueza, de indefinição, que será redefinida pela geração seguinte. Alguns prenomes que antes eram de etnicidade duvidosa são promovidos ao núcleo duro, enquanto novos prenomes vão sendo acrescentados à faixa de indefinição. Talvez seja o caso de se dizer que também aqui a tradição é reinventada. 
O efeito inercial pode ter colaborado para a aceleração que se verifica no aumento do estoque de prenomes. A Tabela 7 apresenta os prenomes (types), suas ocorrências (tokens) nos quatro períodos considerados e a relação numérica entre prenomes e ocorrências (prenomes/ocorrências x 100).

Tabela 7: Número de ocorrências e tipos de prenomes

\begin{tabular}{|c|c|c|c|c|c|}
\hline \multicolumn{2}{|c|}{ SEXo } & 1866-1894 & 1895-1919 & 1920-1939 & 1940-1987 \\
\hline \multirow{3}{*}{ o } & Prenomes & 179 & 306 & 452 & 602 \\
\hline & Ocorrências & 2.448 & 2.756 & 2.013 & 2.706 \\
\hline & Relação & 7,3 & 11,1 & 22,4 & 22,2 \\
\hline \multirow{3}{*}{ o } & Prenomes & 221 & 377 & 486 & 681 \\
\hline & Ocorrências & 2.321 & 2.663 & 1.836 & 2.527 \\
\hline & Relação & 9,5 & 14,1 & 26,4 & 26,9 \\
\hline \multirow{3}{*}{$\hat{o}+q$} & Prenomes & 400 & 683 & 938 & 1283 \\
\hline & Ocorrências & 4.769 & 5.419 & 3.849 & 5.233 \\
\hline & Relação & 8,3 & 12,6 & 24,3 & 24,5 \\
\hline
\end{tabular}

Fonte: Comunidade Evangélica Luterana de Curitiba - Registros de Batismos.

À medida que cresce o estoque de prenomes, o número de ocorrências de cada forma tende a diminuir. Essa relação é expressa por números cada vez maiores; no primeiro período é de 8,3 e no último chega a 24,5, quase o triplo. Trata-se, é claro, de um crescimento explosivo do rol de prenomes utilizados pela comunidade, que se obrigou certamente a redefinir a cada passo os limites de seu fundo étnico.

Quando se confrontam os sexos, constata-se que o estoque feminino inicia e permanece maior que o masculino, conforme as expectativas. No entanto, o ritmo de crescimento do estoque masculino foi ligeiramente maior, como se um fator superveniente determinasse a abertura, mais saliente do segundo para o terceiro período, ou seja, de 1895 a 1939.

A evolução das práticas onomásticas dos imigrantes e descendentes de imigrantes alemães em Curitiba mostra que a história de grupos sociais como estes é atravessada por movimentos e atitudes contraditórias, que não só permitem a mudança, como até podem impulsioná-la. O dilema entre a lealdade à cultura de origem e a necessidade de integrar-se à sociedade hospedeira é objeto de uma negociação a que comparecem soluçôes de ambiguidade - como foi o caso dos prenomes "flexíveis" e dos prenomes portugueses correspondentes aos germânicos - ou de compartimentação social, marcada pela abertura do estoque de prenomes femininos para formas alógenas.

À medida que enfraquece o vínculo com a matriz europeia, os deveres de lealdade se voltam para a comunidade local, que em parte se ritualiza na forma de protocolos sociais, negociáveis, tal como se verificou pelos tratamentos distintos dados aos prenomes do primeiro e do último filho.

O dilema vai sendo recolocado sob novas luzes a cada nova conjuntura, de modo que o trânsito de uma cultura para outra acaba se efetivando com certa facilidade. Cumpre assinalar que, embora a segmentação temporal dos dados não permita aferir o comportamento onomástico de 1930 a 1945, a conjuntura traumática do período Vargas e a ascensão e queda do nazismo particularizaram-se por acontecimentos caoticamente acelerados, determinando um processo de mutação na comunidade. Outros indicadores comprovam que desse quadro resultou um novo grupo de luteranos em Curitiba, cada vez mais evidente a partir do final dos anos 1940. 


\section{Notas}

${ }^{1}$ Pergunta que Julieta faz a Romeu com a intenção de reduzir a importância de ser o sobrenome dele o de família rival. SHAKESPEARE, W. Romeu e Julieta, cena II, ato II. In: Obra completa. Rio de Janeiro: Aguilar, 1969. (v. 1, p. 307).

${ }^{2}$ SCHNAPPER, $1984: 14$.

${ }^{3}$ Para Jean-Pierre Wanier, a identidade é definida como o conjunto dos repertórios de ação, de língua e de cultura que permitem a uma pessoa reconhecer sua vinculação a certo grupo social e identificar-se com ele. (WARNIER, 2003:16).

${ }^{4} \mathrm{Na}$ tradição alemã, as pessoas são individuadas pelos prenomes no ambiente doméstico e nas relações de proximidade social, ficando o sobrenome com essa função nas relaçôes mais distantes. Já entre os brasileiros, a individuação pelo sobrenome é rara e, em geral, ocorre em situaçóes revestidas de cerimônia. Portanto, os migrantes tiveram que fazer também esse ajuste de uso, que representava uma valorização do prenome.

${ }^{5}$ Um mesmo indivíduo pode pertencer a vários grupos, assumindo dessa forma identidades diferentes, com diferentes pesos sociais. Portanto, a correlação entre um prenome e um determinado grupo não exclui que sua escolha seja multideterminada.

${ }^{6}$ A etnicidade teuto-brasileira, ou a ideia de uma germanidade teuto-brasileira imposta por meio de uma ideologia (Deutschbrasilianertum), foi concebida a partir do século XIX e "está vinculada à ideia do pertencimento nacional pelo direito de sangue - uma formulação do nacionalismo alemão". "Como ideologia étnica, traz consigo uma inequívoca proposta de pluralismo étnico-cultural - cada grupo de imigrantes com direito de manter seus costumes, suas (sic) culturas e língua, e todos igualmente cidadãos brasileiros”. (SEYFERT, 1994:17-18).

${ }^{7}$ A rigor, a integração da comunidade imigrante não significa nem sua dissolução nem a perda completa de elementos diferenciadores. O processo é mais lento: a primeira fase da integração consiste na substituição do fundo original por um novo, teuto-brasileiro, que é uma recriação da cultura original no quadro de contradiçôes resultantes do fenômeno de contato (Deutschbrasilianertum). Nessa etapa, os membros da comunidade estarão relativamente integrados, mas ainda conservarão traços próprios. Ultrapassando a integração, a completa "assimilação" constitui, de modo geral, a última etapa de contato do grupo com a sociedade receptora, a qual se cumpre em prazo mais longo.

${ }^{8}$ Os prenomes bíblicos estão entre os mais antigos elementos alógenos da onomástica germânica.

${ }^{9}$ SIEMENS, 1992:IX-X.

${ }^{10}$ É preciso admitir o caráter aproximativo da metodologia empregada, que procura se adequar à realidade dos registros paroquiais e não à realidade viva da comunidade. $\mathrm{O}$ registro pode atestar o batismo de um menino com o nome de Friedrich, mas nada assegura que, no dia-a-dia, não fosse chamado Frederico. Ou o inverso. As diferenças de grafia também são duvidosas: acaso se desfaziam na pronúncia?

${ }^{11} \mathrm{Na}$ Tabela 1, colunas 2, 3, 7, 8 e 9.

${ }^{12}$ São duas listas anuais, uma de prenomes masculinos, outra de prenomes femininos, com igual número de itens, que pode variar de 25 a 35 até 1939.

${ }^{13}$ Disponíveis no citado sítio http://www.beliebte-vornamen.de.

${ }^{14}$ KLAPISCH-ZUBER, 1984:41.

${ }^{15}$ DAUZAT, 1934:36.

${ }^{16}$ L'innovation dans le choix des prénoms - prénoms "nouveaux", doubles ou multiples - s'est-elle portée d'abord sur les prénoms des filles ou sur ceux des garçons? Le statut dévalorisé des filles a-t-il conduit à limiter l'imagination de ceux qui attribuent le prénom, ou bien doit-on penser que les règles de transmission des biens matériels et symboliques concernant de manière privilégiée les garçons, l'imagination peut se déployer à propos des filles puisque, dans ce cas, elle "elle tire moins à conséquence", la pression sociale étant moins forte ? (SCHNAPPER, 198417).

\section{Referências Bibliográficas}

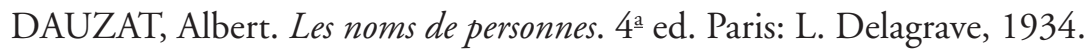

KLAPISCH-ZUBER, Christiane. Constitution et variations temporelles des stocks de prénoms. In: BIDEAU, Alain et al. (Orgs.). Entretiens de Malher (1980). Le prénom, mode et histoire. Paris: Ed. de l'Ecole des Hautes Études en Sciences Sociales, 1984.

SCHNAPPER, Dominique. Essai de lecture sociologique. BIDEAU, Alain et al. (Orgs.). Entretiens de Malher (1980). Le prénom, mode et histoire. Paris: Ed. de l'Ecole des Hautes Études en Sciences Sociales, 1984.

SEYFERT, Giralda. A identidade teuto-brasileira numa perspectiva histórica. In: MAUCH, Cláudia; VASCONCELLOS, Naira. Os alemães no sul do Brasil. Canoas: Ed. Ulbra, 1994. 
SHAKESPEARE, William. Romeu e Julieta, cena II, ato II. In: SHAKESPEARE, William. Obra completa. Rio de Janeiro: Aguilar, v. 1, 1969.

SIEMENS, João Udo. Os prenomes dos descendentes de alemães em Curitiba. São Paulo: Tese de Doutorado, Universidade de São Paulo, Curso de Pós-Graduação em Letras, 1992.

WARNIER, Jean-Pierre. A mundialização da cultura. Bauru: Edusc (Editora Universidade do Sagrado Coração), 2003.

\section{RESUMO}

$O$ artigo estuda os prenomes de batismo atribuidos a meninos e meninas de uma comunidade luterana e evangélica em Curitiba, constituida na origem por imigrantes alemães e seus descendentes. Os dados colbidos junto aos registros de batismos, que se estendem de 1866 a 1987, foram objeto de uma classificação em tipos e de uma análise frequencial. Os resultados permitiram estabelecer relaçōes entre as práticas onomasiológicas e o processo de integração desse agrupamento étnico e religioso à sociedade receptora. Submetidos à tensão entre a lealdade a suas origens e a necessidade de se adaptar ao novo mundo, os membros da comunidade exploraram dois procedimentos de ambiguidade: utilizar prenomes que podiam ser interpretados quer como germânicos quer como brasileiros, e intensificar a internacionalização dos prenomes femininos, compensando assim a preservação dos prenomes masculinos germânicos. Dessa maneira alcançaram uma solução de compromisso que, nessa área organização social, thes permitiu a integração sem a perda da identidade.

Palavras-chave: Demografia Histórica, Paraná - Brasil.

\section{ABSTRACT}

This article carries out a study of the baptismal names given to the boys and girls of a Lutheran and evangelical community in Curitiba, originally composed of German immigrants and their descendants. The data gathered from the baptism registries dating from 1866 to 1987 were classified by types and were the object of a frequential analysis. The results helped establish relationships between the onomasiological practices and the integration process of this ethnic and religious group into the receiving society. Subjected to the tension between their loyalty to their origins and the need to adjust to the new world, the members of this community used two different ambiguous procedures: using first names that could be considered both Germanic and Brazilian, and intensifying the internationalization of feminine baptismal names, thus preserving Germanic masculine first names. Therefore, they found a compromise solution which, in this area of social organization allowed them to be integrated without losing their identity.

Keywords: Historical Demography, Paraná - Brasil. 